\title{
THE EARLY STAGES OF THREE COLEOPTERA.
}

\author{
BY SAMUEL H. SCUDDER.
}

Finding among some old papers notes of the early stages of certain Coleoptera imperfectly known, I venture to print them. All the species were found upon sweet fern.

\section{MEGILlA MACULATA.}

The full grown larva has the head shining black, faint yellowish in centre. Body black above, brown beneath, except two yellow spots on the edge of the fifth abdominal segment; first thoracic segment with transverse yellow bands at front and hind edges; the second and third with a yellow dorsal stripe; second abdominal segment, except the middle third, yellow, fifth abdominal wholly yellow, and the other segments with a row of yellow spots on each side. Besides there are twelve longitudinal series of black papillae, six on the upper and six on the under surface, one to a segment in each series, those on upper larger than those on under surface, each giving rise to a short black hair.

The pupa is in general black. Head with a median yellow line. Thorax with a dorsal yellow stripe, a median transverse band and a stripe at the sides reddish yellow; from these a dorsal and lateral stripe of the same color pass backward and broaden in the middle of each segment, the first abdominal segment thus entirely reddish yellow except a subdorsal black spot on either side; besides in the interstices of the abdominal segments are other minute yellow and black spots; the thoracic appendages are black and the markings of the elytra of the future imago cannot be seen; ventral surface of abdominal segments white.

The hind legs protrude oddly on either side of the body beneath the elytra like two side horns, and the legs of the cast larval skin sprawl about the tail of the chrysalis, the last segment being immersed therein. When quiet, the chrysalis lies on the surface of rest, but if disturbed, it erects its whole body at right angles thereto, and then the interstitial markings of the abdomen are concealed. One individual changed to chrysalis on August 24. (Notes of I859.)

\section{COCCINELIAA SANGUINEA.}

The full grown larva has a small black head and a dusky body; in the middle of either side of each thoracic segment is a large black spot, covering nearly the whole surface on the first segment which is bordered anteriorly with dull orange; there is a dull orange dorsal band of irregular width along the whole body, its limits vague, and besides, on the abdominal segments, subdorsal, lateral and stigmatal series of black spots, one to erch segment; on the sides of the first five abdominal segments are found some dull orange spots; the body beneath is dusky with a rather dull orange broad ventral band; the legs are black. Length $9 \mathrm{~mm}$.

The pupa is in general of a dusky yellow; the head is black; thorax with a yellowish dorsal line and on either side of it at the posterior edge of each segment a black spot; the first thoracic segment has also another lateral black spot on posterior edge and a large black spot on the front edge; the wings and all the thoracic appendages are black where exposed; but otherwise apparently dusky or pale yellow; the abdominal seg- 
ments are dirty white or black with yellowish spots, the first two segments having a predominance of yellow, the others of black; the ventral surface is dirty white or yellowish.

Two specimens changed to imago on September roth at Cape Cod after eight days in pupa. (Notes of $186 \mathrm{r}$.)

The pupa is figured by Comstock (Rep. U. S. entom. for I88r, pl. I8, fig. 4) and the larva by Candèze (Mém. soc. sc. Liége, vi, pl. 6. fig. 7.).

\section{CHLAMYS PLICATA.}

The larva of this beetle may be found abundantly the last of July and early in August hanging perpendicularly with its case from the under side of leaves of sweet fern.

It has an orange yellow body, deepening in tint toward the tail with a delicate suffusion above of light olivaceous green, but the head and long legs are jet black, and the dorsum of the thorax and the parts above the legs are of a dark testaceous. The whole body is sparsely covered with microscopic hairs, and one notes a depression in the middle of the dorsum of the last segment.

When taken from its case the tail is curled under its body and this is evidently its normal attitude.

The larval cases are from five to six millimetres long for the full grown creature, and at the most about three millimetres broad. They are smooth within but externally rough, black, oval, the oblique open end generally minutely flaring with a more or less distinct notch above and below, and especially below, for the better use of the legs; it looks as if made of black papier maché and is evidently formed by accretion, as may best be seen by examining the under surface where there is an indistinct median groove, where the bands of accretions on either side seem to have been brought together. These accretions are laid on apparently at about ten or twelve times during the life of the larva, in an oblique course, broadest on the back and narrowest on the ventral side. According to Riley and Murtfeldt it has as its basis "a covering of dark sticky excrementitious matter... somewhat bell shaped, the upper end being largest, squarely docked and slightly depressed so as to form a circular rim around the margin" which the female constructs to cover the egg, and which is cut away from its attachments by the larva when born and made the basis of its movable house. The manner of enlargement has yet to be told.

The larva crawls with some rapidity, and when it retreats within its case it is wholly beyond the deepest cleft, the claws of the feet only projecting therefrom. When one is forcibly removed, it seems unable to get back again; at least such as I have experimented upon have failed to do so, though they tried hard to do so by going in head foremost; they succeeded in getting only the head and three of the legs inside, the length of the legs appearing a hindrance.

Before changing to pupa they turn around in the sac so that the anal extremity is toward the former opening, which is now closed, since in prepara- 
tion for the change they glue this end tightly to the surface of a leaf, and with such a superfluity of substance as to make this end of the interior rounded.

At first the pupa retains the bright yellow color of the larva, the eyes and tips of the mandibles being black, and the outer surface of the legs and wings and especially the incisures of the legs infuscated. Afterwards when nearing the final change, the pupa assumes the color of the beetle, a brilliant deep bronze, though the abdominal rings, especially at the tip, still retain somewhat of their original yellow.

The pupal state lasts nearly four weeks in Massachusetts, in one instance from Aug. 4 to Aug. 3o. The pupa seems to be free, moving at least its head and hinder legs with ease; in the change the old skin is thrown off as a thin transparent pellicle, which looks as if only large enough to cover the end of the abdomen, while the old larval skin may be discovered packed tightly away next the old opening. By using its jaws upon the end of the case with which they are in contact, the enclosed beetle succeeds in making little transverse cuts around the former bottom of the sac until finally the old egg-covering with a little more is lifted at the single part of the bitten circle remaining as at a hinge, and the beetle presents himself with all his fresh beauty to the world.

I once found on July ${ }_{5} 5$ a case glued to a fern leaf, and noticing a series of fine holes around the glued end I opened it and discovered the larva in position for change to pupa, but lying against its middle the pupa of a hymenopterous parasite of a uniform light amber color with deep amber eyes and about $\mathrm{I} .75$ $\mathrm{mm}$. long. Five days later I noted change in color and discovered that the body of the Chlamys larva was simply crammed with similar hymenopterous pupae, twenty-three in all; three days later they emerged, but unfortunately were never determined and are now lost. When the pupae had gained their color, however, the dorsal portions of the abdominal segments were very dark brown, almost black, with a few indistinct transverse yellowish streaks and a similar streak across the thorax just behind the head; there are three ocelli in a row on the top of the head between the eyes; the hind legs just reach the tip of the abdomen but the other legs, like the hind legs appressed to the sides of the body, are short.

Other larval cases similarly attacked were found where the parasites had left the case ragged at the end opposite to the glued part where they had made their escape.

There are apparently at least two broods of this beetle which I have found in the latter part of July and in the latter part of August and early in September. Probably the beetles hibernate. (Notes taken in I859-186r.)

The larva and its case are figured by Riley (Rep. ins. Missouri, vi, fig. 37 on p. I3O). 

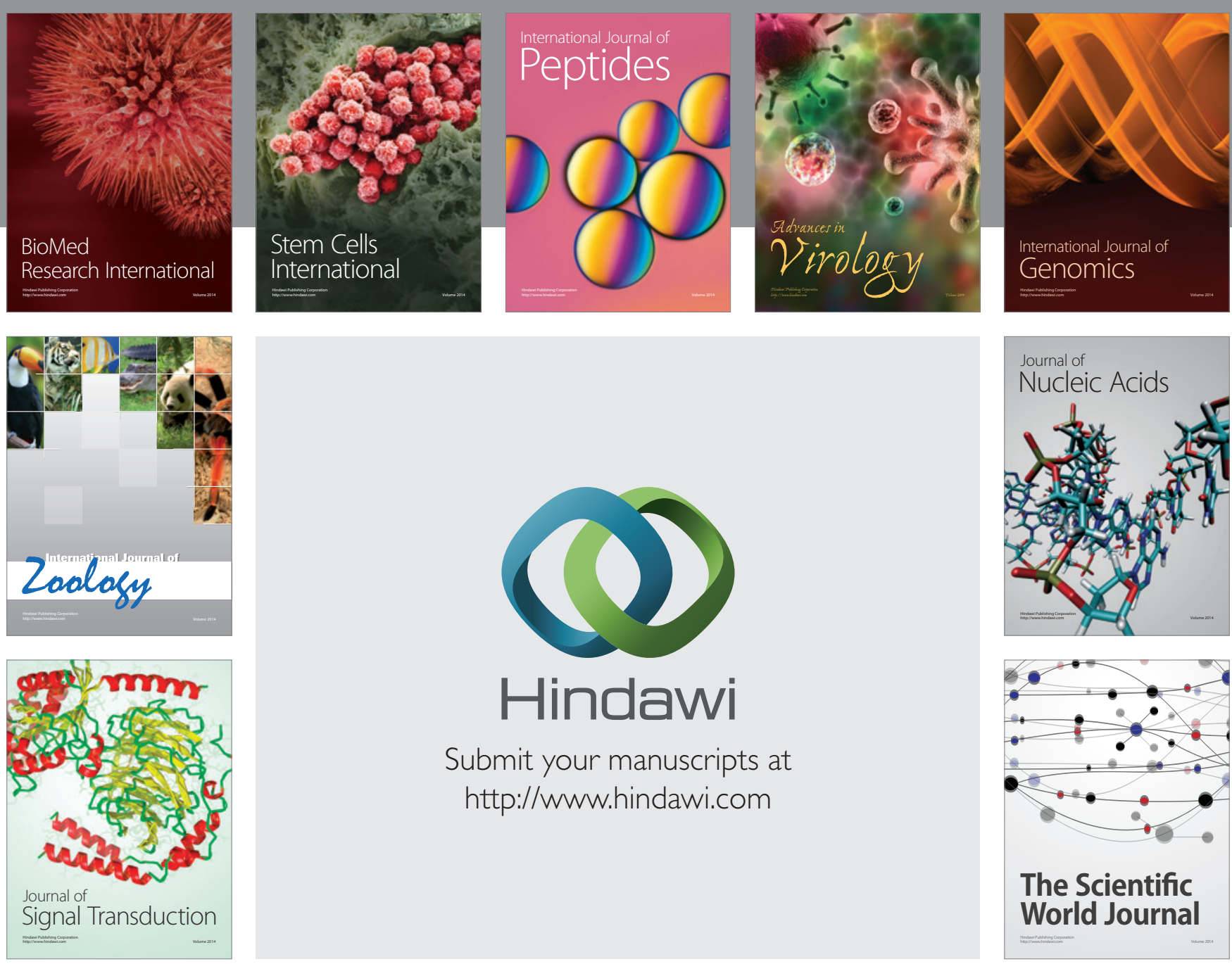

Submit your manuscripts at

http://www.hindawi.com
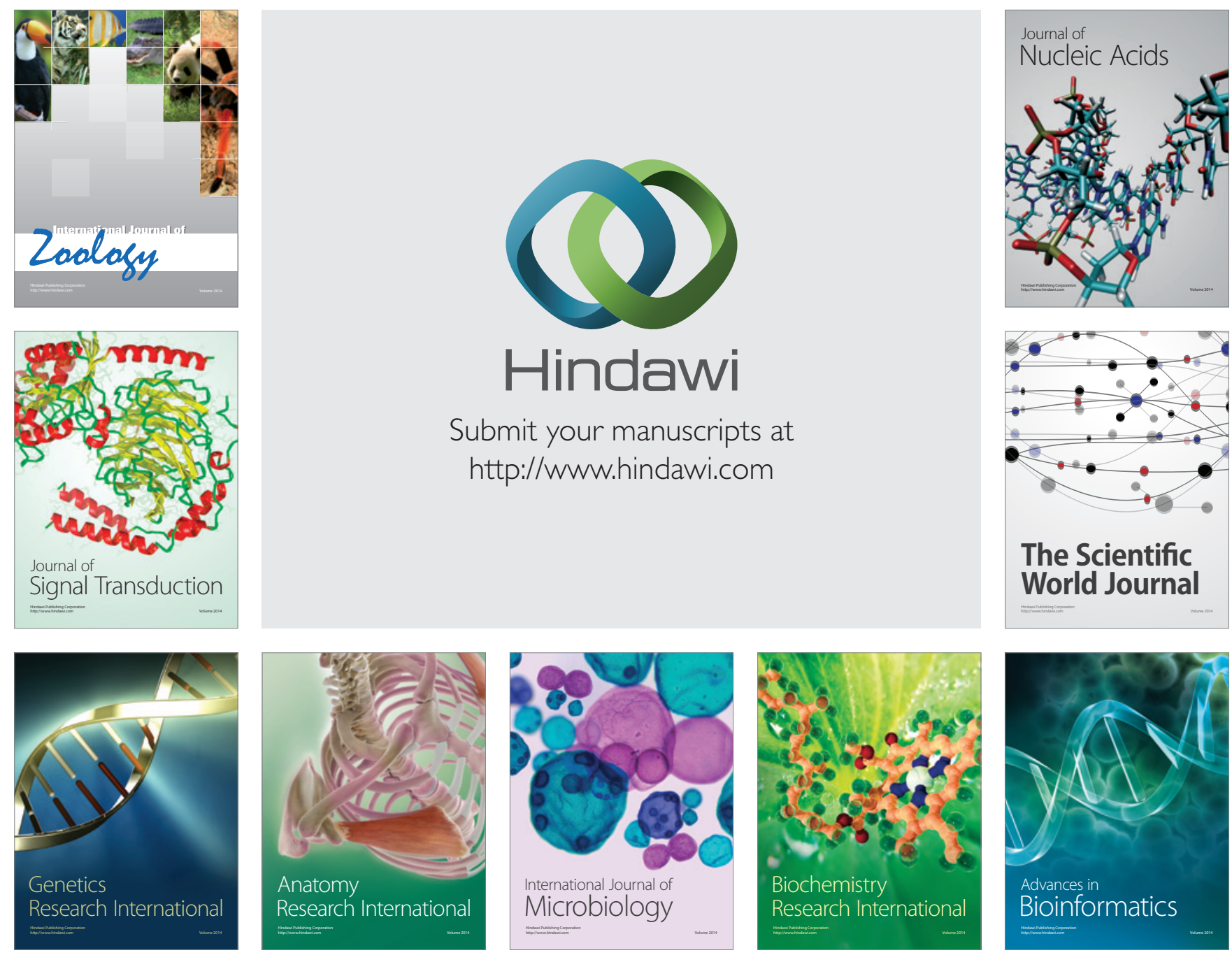

The Scientific World Journal
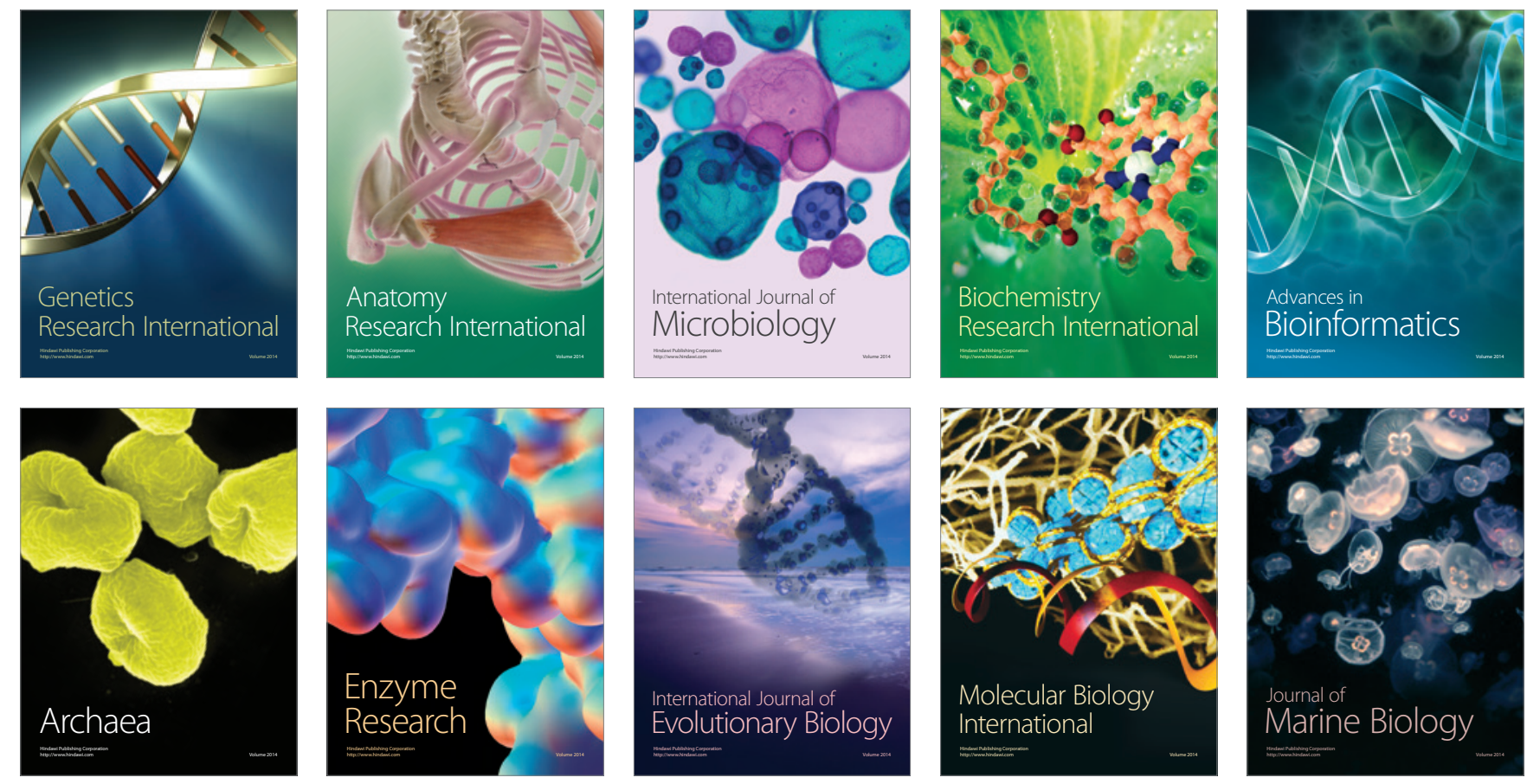